Abstracta Iranica Iranica

Revue bibliographique pour le domaine irano-aryen

Volume 32-33 | 2013

Comptes rendus des publications de 2009-2010

\title{
Vito Messina. Seleucia al Tigri, Il monumento di Tell 'Umar. Lo scavo e le fasi aechitettoniche
}

\section{Rémy Boucharlat}

\section{(2) OpenEdition}

1 Journals

Édition électronique

URL : http://journals.openedition.org/abstractairanica/40552

DOI : 10.4000/abstractairanica.40552

ISSN : 1961-960X

\section{Éditeur :}

CNRS (UMR 7528 Mondes iraniens et indiens), Éditions de l'IFRI

\section{Édition imprimée}

Date de publication : 1 décembre 2013

ISSN : 0240-8910

\section{Référence électronique}

Rémy Boucharlat, "Vito Messina. Seleucia al Tigri, Il monumento di Tell 'Umar. Lo scavo e le fasi aechitettoniche », Abstracta Iranica [En ligne], Volume 32-33 | 2013, document 186, mis en ligne le 01 juillet 2016, consulté le 27 septembre 2020. URL : http://journals.openedition.org/abstractairanica/ 40552 ; DOI : https://doi.org/10.4000/abstractairanica.40552

Ce document a été généré automatiquement le 27 septembre 2020.

Tous droits réservés 


\title{
Vito Messina. Seleucia al Tigri, Il monumento di Tell 'Umar. Lo scavo e le fasi aechitettoniche
}

\author{
Rémy Boucharlat
}

\section{RÉFÉRENCE}

Vito Messina. Seleucia al Tigri, Il monumento di Tell 'Umar. Lo scavo e le fasi aechitettoniche, (Centro Ricerche Archeologiche e Scavi di Torino per il Medio Oriente e l'Asia. Missione in Iraq IV). Firenze, Le Lettere, 2010, VII-209 p., fig., 2 plans dépliants h.-t.

1 Nouveau magnifique volume de la publication finale des fouilles italiennes à Séleucie de 1964 à 1976. Deux autres volumes traitaient du Bâtiment des Archives, les empreintes de sceaux qu'il contenait par A. Invernizzi, l'autre de l'architecture et de l'évolution du bâtiment par V.M. en 2006, (cf. Abs. Ir. $29 \mathrm{n}^{\circ} 120$ et 123). Saluons d'abord l'effort constant de la mission de Turin pour publier.

2 Ce volume traite plus largement des fouilles, en présentant d'abord les fouilles ellesmêmes, l'état des ruines, la chronostratigraphie en huit niveaux couvrant la période de 300 av.n.è. au $\mathrm{VI}^{\mathrm{e}}$ s. d.n.è., et leur relation aux résultats des fouilles américaines de l'entre deux guerres. Le chap. 2 présente les vestiges du niveau (VIII), le plus ancien, du $\mathrm{III}^{\mathrm{e}} \mathrm{s}$., dont l'organisation de l'architecture en briques crues est difficilement restituable, malgré son caractère monumental, du fait de l'accumulation des niveaux postérieurs. Le plus important chapitre 3 concerne les niveaux VII-VI, séleucides, à II, époque parthe jusqu'au $\mathrm{II}^{\mathrm{e}} \mathrm{s}$. de $\mathrm{n}$. è., et, dans ceux-ci, les fouilles du théatre et de la partie orientale de l'agora (le bâtiment des archives bordait celle-ci à l'ouest). Il fallait un travail de bénédictin pour décortiquer ces énormes volumes de briques crues qui d'un niveau à l'autre s'appuient, en les modifiant, les constructions antérieures. Le théâtre en particulier est un massif de briques crues sur des centaines de mètres carrés et des mètres d'épaisseur. Les fouilles d'une partie de la cavea permettent la restitution 
de celle-ci (fig. 168) et offrent d'utiles comparaisons avec des théâtres contemporains, d'abord avec celui de Babylone, tout proche, jusqu'au monde grec occidental mais aussi Aï Khanum en Afghanistan. Fondé au tournant du $\mathrm{III}^{\mathrm{e}}$ et du $\mathrm{II}^{\mathrm{e}} \mathrm{s}$. av. n.è., le théâtre survivra, avec des réparations jusqu'au début du $\mathrm{II}^{\mathrm{e}} \mathrm{s}$. de n. è., avant de tomber peu à peu en ruines dans le courant de ce siècle et au début du III ${ }^{\mathrm{e}} \mathrm{s}$., intéressante survivance d'un type d'architecture et d'une fonction liées à la culture de segments de populations d'origine ou marquée par la culture hellénique.

3 Le niveau II, fin parthe et sassanide, correspond à une longue période d'abandon de cette partie de la ville, dont les témoins les plus nets sont les sépultures de plusieurs types : inhumations de corps en position allongée, nouvelle pratique qui se répand dans la Mésopotamie de cette époque, dans des sarcophages de terre cuite, ou des caissons en briques crues, ou bien de corps en position contractée dans jarres, usage traditionnel de la Mésopotamie. La dernière occupation au $\mathrm{VI}^{\mathrm{e}} \mathrm{s}$., concerne la partie orientale du secteur fouillé ; elle est marquée par une énorme muraille en briques crues de plan elliptique, installée en partie sur les ruines du théâtre et, au centre de celle-ci une imposante tour quadrangulaire (Restitution de l'ensemble fig. 250). Depuis plusieurs siècles, l'activité de l'ancienne capitale séleucide s'était déplacée à Ctésiphon. Cette recherche minutieuse complète l'histoire d'une des plus importantes cités du Moyen-Orient, pendant la période des grands empires post-achéménides et antérieurs à la période islamique.

\section{AUTEURS}

\section{RÉMY BOUCHARLAT}

CNRS, Lyon 